\title{
Spectral Enhancement and Automated Extraction of Potential Sinkhole Features from NAIP Imagery - Initial Investigations
}

\author{
J. S. Dinger ${ }^{1 *}$, D. P. Zourarakis ${ }^{2}$ and J. C. Currens ${ }^{1}$ \\ ${ }^{1}$ Kentucky Geological Survey, University of Kentucky, Lexington, KY, 40506-0107 USA \\ ${ }^{2}$ Kentucky Division of Geographic Information, Commonwealth Office of Technology-Division of \\ Geographic Information, Frankfort, KY 40601 USA
}

\begin{abstract}
In eastern USA, karst sinkholes are responsible for millions of dollars of damage to buildings, infrastructure, agribusiness, and land availability. Drilling and geophysical techniques have been employed to locate developing sinkholes that have not yet expressed themselves at land surface through cover collapse, but these techniques are expensive and time consuming if not targeted to specific, small areas. This paper presents initial research into locating cover-collapse sinkholes through the use of aerial remote sensing. National Agricultural Imagery Program imagery, captured in the summer of 2004 with 1-m ground resolution, in 3, 8-bit bands (visible, RGB), was found to be effective in highlighting circular features that appear to be related to sinkhole occurrence on two farm sites. In some instances, the features were sinkholes up to $5 \mathrm{~m}$ in depth. In other instances, the features did not represent existing sinkholes but potential sites of incipient cover collapse. Differences in agriculturally related vegetative cover at this time affected the efficiency of determining the extent of karst development. Surface geophysical techniques and drilling will be used to characterize the subsurface when cropping practices allow. The goal is to correlate imagery features to subsurface characteristics so that remotely sensed imagery can be used as a means of delineating potential cover-collapse sinkholes before they express themselves at the surface. Development of such a tool will provide a time- and cost-effective approach to land-use planning and, therefore, substantially reduce damage done by cover collapse.
\end{abstract}

Keywords: Cost, cover collapse, feature extraction, karst, linear, remote sensing, spectral enhancement

\section{Introduction}

This paper presents initial efforts to develop remote sensing techniques to locate hidden, underground cover-collapse sinkholes before they collapse. Such collapse generally occurs with minimal warning and most likely impairs the ecology, water resources, and landuse; may cause excessive damage to anthropogenic structures; and threatens animal and human life (White and White, 1992; Sowers, 1996). Drilling and geophysical techniques including ground penetrating radar, microgravity, electrical resistivity and seismic have been used to with varying success to locate sub-surface voids that may collapse in the future. However, these techniques can be expensive from both an instrument cost and the time necessary to employ them successfully in the field (Woods, 1994; Sowers, 1996; Baughman, 2006). A significant part of that cost is the many man hours necessary to delineate a void even when the general location of the void is known. For delineating potential cover-collapse sinkholes over large land areas known to have voids but where even their general locations are unknown, the process of drilling or employing geophysical methods is daunting from manpower needs, physically moving the equipment across large tracks of land due to topography relief and vegetation, and arranging for landowner permission

\footnotetext{
* Corresponding author: dinger@uky.edu
}

to be on property. For these reasons, there is a critical need to develop remote sensing techniques that can rapidly and costeffectively identify the location of potential cover collapse sinkholes. Once these concise areas are identified, drilling and geophysical techniques may be used more cost effectively to enhance further details as necessary.

In this paper we discuss the application of remotely sensed digital imagery, and the initial field checks of two sites where sinkholes are known to exist. The ultimate goal of this research is to develop remote sensing techniques to delineate the location where the potential cover collapse sinkholes will form without incurring unnecessary costs for drilling or applying geophysical techniques.

\section{Imagery}

Digital imagery presents the opportunity for applications by environmental and natural-resource information specialists to extract information as GIS (raster or vector - feature) layers from remotely sensed data. Identification and feature extraction from digital imagery using manual photo-interpretation and heads-up digitization is laborious, time consuming and requires trained specialists, all of which lead to a high cost of analysis. As a viable alternative, the spectral enhancement and semi-automated feature extraction with machine-learning software is becoming increasingly commonplace (O'Brien, 2003). 


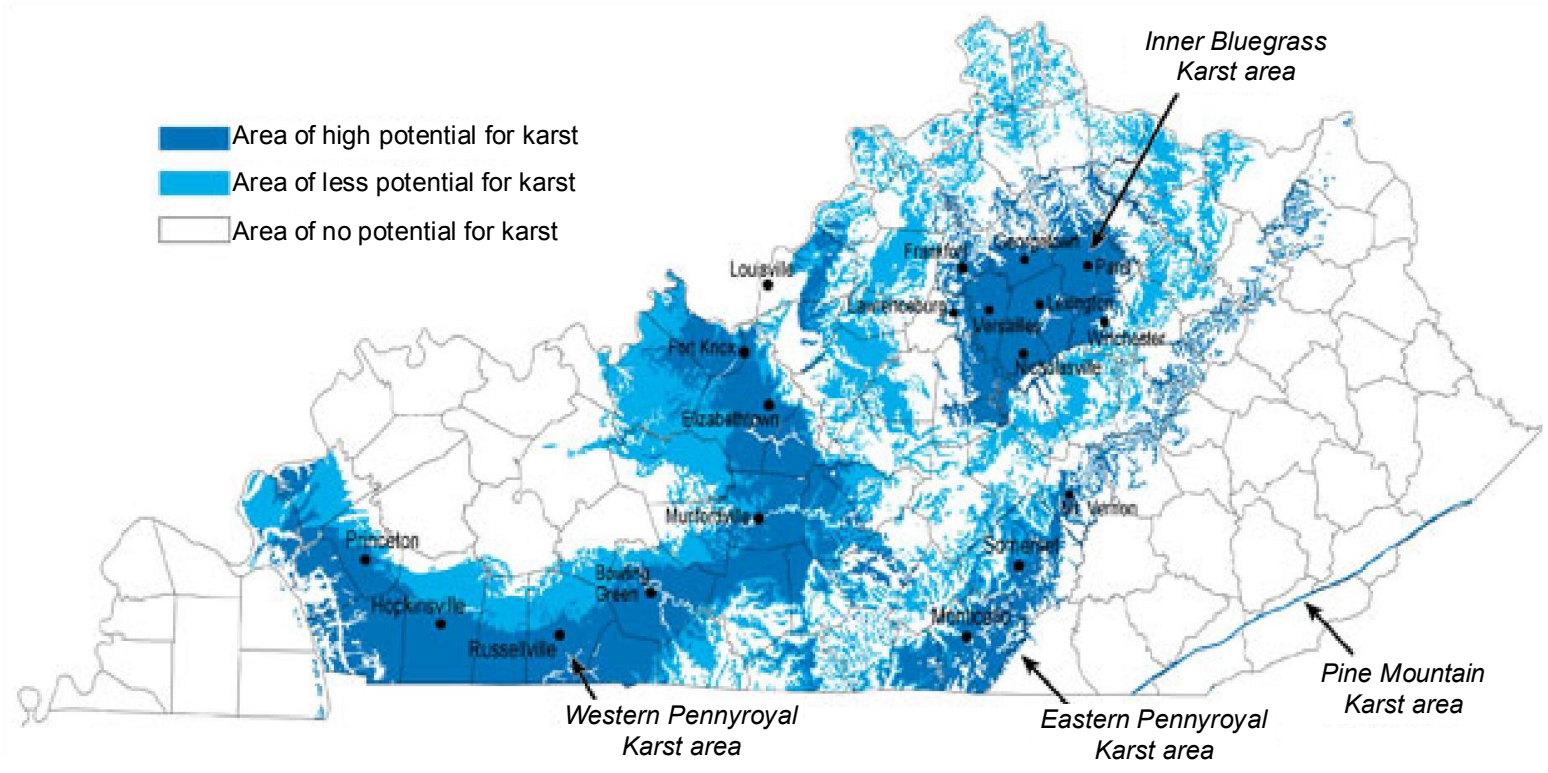

Figure 1. Map showing degrees of potential karst development in Kentucky (Currens et al., 2005).

Kentucky recently purchased current, state-wide, high-resolution digital orthophotography from the National Agricultural Imagery Program (NAIP). This imagery was acquired for the 2004 growing season (leaf-on, late spring/early summer), at 1-m ground resolution, in 3, 8-bit bands (visible, RGB). Following the re-projection of the original data, this imagery was used by the Kentucky Division of Geographic Information (DGI) to update the state's base map, served by DGI's various Web mapping services or "portals" (e.g. the Commonwealth Map at: http://kygeonet.ky.gov/tcm/viewer. htm). The imagery is also available for downloading, adding to the state's significant data holdings, collectively known as the KY Geonet: (http://kygeonet.ky.gov).

\section{Karst Topography}

Approximately 20 percent of the United States of America (USA) contains carbonate bedrock - most commonly limestone units, which entertain the development of karst topography. Ninety percent of karst topography is east of the Mississippi River. Carbonate bedrock capable of developing karst terrain occurs in 55 percent of Kentucky of which approximately 25 percent can be considered to be intensely karst (Figure 1). In an effort to mitigate karst hazards, a limited number of engineers, hydrogeologists, and landuse planners in Kentucky have been studying sinkhole formation with the goal of predicting the future occurrence of sinkholes (Dinger and Rebmann, 1986; Veni and Crawford, 1988; Taraba et al., 1997; Currens and Graham, 1993; Crawford and Groves, 1995; Currens, 1999; Currens et al., 2003).

Collapse of land surface (cover collapse) through sinkhole development often leads to damage or destruction of infrastructure and buildings, with a potential cause of subse- quent surface flooding. It is dangerous to life, both agricultural animal and human life, and damages farm equipment. Because damage occurs in isolated instances and is scattered across the Commonwealth, it is difficult to obtain exact costs related to sinkhole development. We conjecture from anecdotal evidence, that the costs associated with this damage in Kentucky are approximately $\$ 23$ million per year (Table 1). It is fortuitous that no human lives have been lost in Kentucky to this activity although there have been injuries. The breeding and training of thoroughbred race horses in Kentucky is a multi-million dollar a year industry. Documented case histories are seldom made public, but reliable anecdotal reports indicate that horses have died due to falls into newly formed, un-fenced sinkholes on horse farms. A single such loss could be in the millions of dollars (Kara Vittitow, DVM, Lexington, Kentucky, oral commun.) and would, therefore, add signifycantly to the estimated damage caused by the formation of cover-collapse sinkholes. Similar types of undocumented losses in other agribusiness should be assumed.

Table 1. Estimated Cost of Karst Hazards in Kentucky

\begin{tabular}{ll}
\hline Karst-Related Item & Cost per Year $(\$)$ \\
\hline Property damage & 500,000 \\
Sinkhole repair: & \\
$\begin{array}{l}\text { \$2K/sinkhole/10,000 sinkholes in state's } \\
\text { intensively karst area (25\% of the state) }\end{array}$ & $20,000,000$ \\
Increased construction cost & $2,000,000$ \\
Flooding damage & 500,000 \\
Total cost per year & $23,000,000$ \\
\hline
\end{tabular}




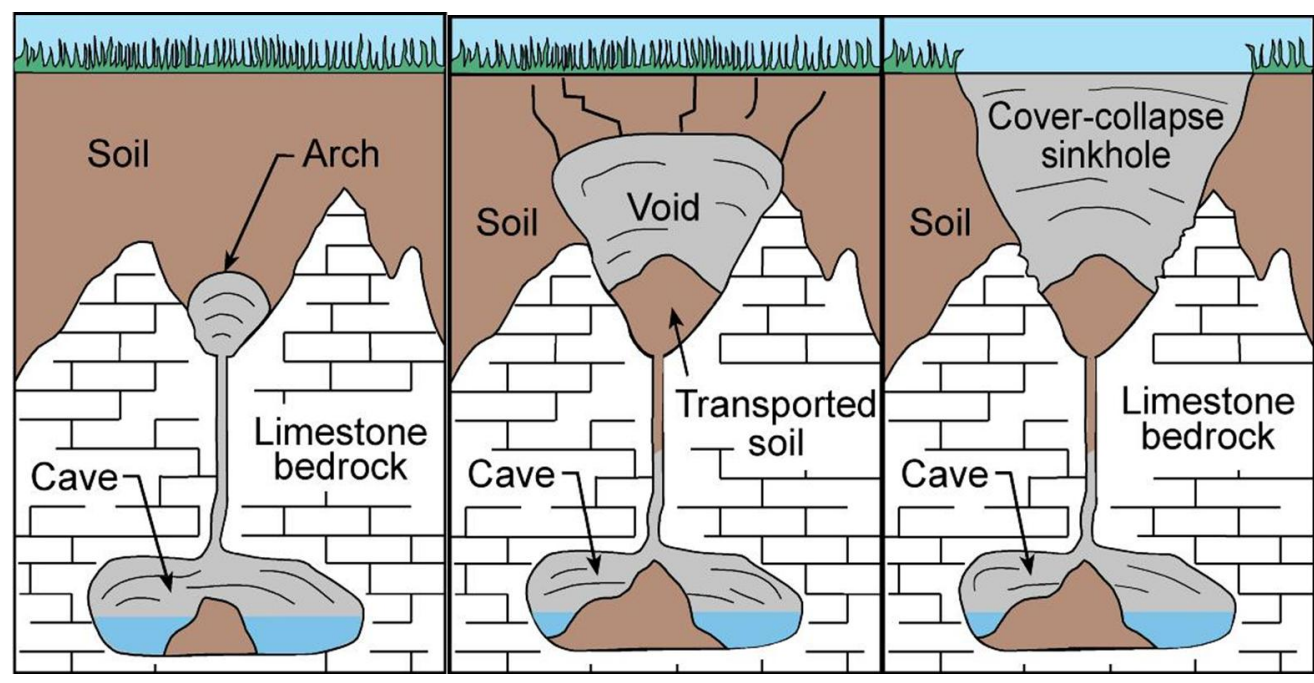

(a)

(b)

(c)

Figure 2. Sequence of bedrock dissolution leading to land-surface cover collapse that forms a sinkhole.

Even in areas where karst terrain are prominent, the appropriate planning for and placement of anthropomorphic features have only recently been recognized by planners, engineers, and the agricultural community. The usual sequence of events is to build and then react to the karst activity as it occurs, many times decades after construction on the land surface.

Figures $2 \mathrm{a}$ through $2 \mathrm{c}$ are schematics depicting the sequence of how cover-collapse sinkholes develop in a process caused by erosion of the soil arch above a solution feature in the bedrock. Figure 2a shows the beginning of the development of subsurface soil erosion at the top of a dissolution conduit in the bedrock. Either water moving down through the soil profile to the bedrock or a rise in groundwater upward through an existing cave passage weakens the soil which begins to slump down through the bedrock forming a void in the soil. As this process continues through time, the soil void continues to grow upward and eventually leave a thin soil arch above the void (Figure 2b). Ultimately, this soil arch becomes so thin that it does not have the strength to support itself, and cover collapse occurs to form a sinkhole (Figure 2c). The length of time for this sequence to occur is undetermined but we estimate that the latter two stages can be rather rapid, potentially within a few years, depending on many hydrogeologic variables such as soil type, amount of rainfall infiltration, and fluctuation in the water table. Typically in the eastern portion of the USA, cover-collapse sinkholes range in diameter from 0.5 meters up to tens of meters, and can range from one meter to fifteen or more meters in depth.

Unfortunately, the formation of sinkholes is often acelerated after human intervention in a location due to alteration of water movement throughout the site. Sinkholes also increase the potential for environmental hazards because they provide rapid and direct path for surface water to enter groundwater systems.
A cost-effective method for early identification of potential sinkhole sites would be a tremendous benefit to land-use planners, agriculturists, and environmentalists. The purpose of this current research is to develop a methodology to use the remotely sensed imagery to predict future sites of sinkhole development. In addition to observable, mapped or unmapped sinkholes, it is our hypothesis that the beginning stages of formation of these features may be observable on satellite and airborne images because of the seasonal moisture stress they exert on vegetative cover over the soil arch (Figure 2b).

\section{Methodology}

Rouse et al. (2004) used Landsat 4 imagery to analyze moisture stress in vegetation as a tool to locate potential cover-collapse sinkholes. Unfortunately, the medium to low spatial resolution of their imagery ( $82 \mathrm{~m}$ for MSS and $30 \mathrm{~m}$ for all TM bands, except the thermal) was found to be one of several severely limiting factors in obtaining conclusive results. Stombaugh et al. (2003) recognize that cost of appropriate, finer-resolution imagery is a significant roadblock to investigating vegetative cover at a scale pertinent to perform subsequent, expensive on-site field determinations. To overcome this expense, we have chosen natural (true) color, 1 meter, NAIP digital orthophotography which was recently purchased by the Commonwealth for multiple uses thereby minimizing the cost to this karst research. Digital NAIP orthophotography covering 4 quarter quadrangles was mosaiced, and histogram matched. The original projection (UTM Zone 16 North, NAD83, in meters) was preserved. Spectral enhancement of the images was performed by applying décorrelation stretch (Lillesand et al., 2004). This technique, commonly employed to bring out faint patterns and obscured features in an image, was utilized to identify areas of potential interest (Gillespie et al., 1986). 
Two farms on the Cadiz USGS 7.5 Minute Quadrangle in Trigg County were selected to test proposed image processing methodologies (Figure 3). The River Bend Farm and the Steve Newton farm were selected because of their known sinkhole occurrence, and the fact that we had cooperation of the farm owners. The original NAIP imagery was enhanced spectrally by performing decorrelation stretch, utilizing ERDAS ${ }^{\circledR}$ Imagine 8.7. At the time the imagery was acquired in 2004, a wheat crop was approaching maturity at both farms. It is possible that differences in crop phenology, plus other factors such as disease, pests, nutrient or moisture stress contributed to the manifestation of geologic (surficial plus subsurface) features and processes.

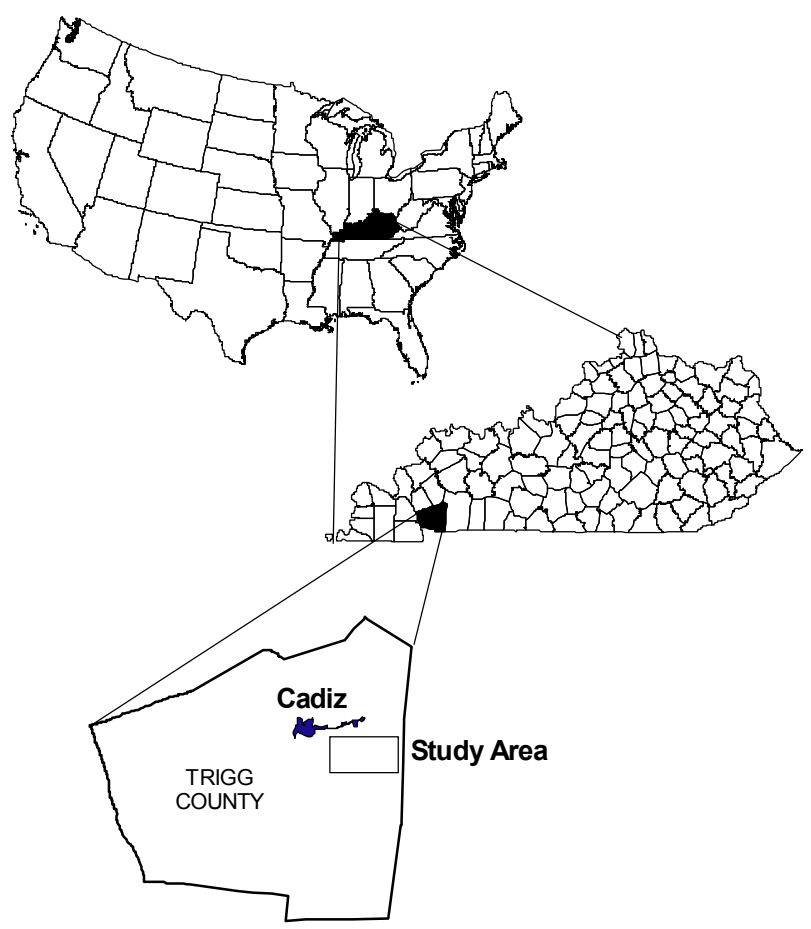

Figure 3. Map showing location of study area near the town of Cadiz, Trigg County, Kentucky, USA.

\section{Results}

\subsection{Newton Farm}

Two images of the Newton Farm, original RGB NAIP and spectrally enhanced are shown in Figures $4 \mathrm{a}$ and $4 \mathrm{~b}$, respectively. Prominent, circular shapes stand out. The software used to extract feature layers from the imagery, Feature Analyst $^{\mathrm{TM}} 4.0$ extension for ArcGIS ${ }^{\mathrm{TM}} 9.1$, was "trained" by a human analyst on a very small subset of features visible on the decorrelation-stretched image. The software, which operates on the base of proprietary, heuristic learning algorithms, was run utilizing a Manhattan input representation with a 13-pixel pattern width. The resulting output, a polygon feature layer shown in Figure 4c, retains the pattern revealed in the source image.
The most predominant circular shapes are light green. These circular shapes have a rather consistent diameter ranging from approximately 25 to $45 \mathrm{~m}$. Two groups of these circulars appear to form curvilinear patterns in some portions of the image to form lineaments. Both lineaments trend westnorth-west (see Figure 4a, Linears 1 and 2). The less predominant circular shapes are brown-green in color and they also form a linear in the same geographical orientation (see Figure 4a, Linear 3).

The soil mapping units in this area are Hammack silt loam on 2 to 6 percent slopes, Hammack-Baxter Complex on 6 to 12 and 12 to 20 percent slopes, with minor areas of Lindsey silt loam (Humphrey, 1981). Thus, the area is dominated by Typic Paleudalfs, which are deep, well drained, but eroded and eroding soils. Although a Nicholson on 2 to 6 percent slopes mapping unit is present at the fringe of the area, fragipans are absent in the mapping units dominating the area addressed in this study. A field visit to this site in April, 2006, revealed that the fields are covered in corn stubble from last summer's crop (Figure 5). The stubble is approximately $0.5 \mathrm{~m}$ high and much of it is bent over to the ground surface. The brown-green circular shapes are active sinkholes as great as 5 $\mathrm{m}$ in depth (Figure 6). Some open throats are present at the bottom of the sinkholes, and some throats are choked with sand-size sediment. In both cases it is apparent that surface water is draining into these sinkholes which are transferring surface runoff to the groundwater system.

The two linears formed by the light-green circular shapes have different topographic settings. Linear 1 parallels a moderate slope and represents a slight leveling of this slope to form a semi-flat surface (see Figure 5). Its surface has occasional epikarst swallow holes approximately 2.5 to $6 \mathrm{~cm}$ in diameter (Figure 7). However, there is no confluence of surface-water drainage to provide any sort of a semblance of sinkhole development like that described above along Linear 3 (see Figures 4 and 6).

Linear 2 is a low lying area on which surface water drains from the field toward and then down the north trending, narrow, steep-sloped surface drainage bordered by trees (see Figure $4 \mathrm{a}$, point $\mathrm{A}$ ). There are several shallow depression along the Linear 2 (see Figure 4, features B, C, and D), and a narrow erosion furrow between features $\mathrm{B}$ and $\mathrm{C}$ with a noticeable knick point (Figure 8) However, there is no appearance of sinkhole development along this linear nor were any epikarst swallow holes observed.

Confirmation with the Cadiz 7.5 Minute USGS Geological Quadrangle map (Fox, 1965) indicates that Linears 1 and 2 fall along a fault forming the northern boundary of a graben extending to the south that is approximately $2 \mathrm{~km}$ wide. Future work at the Newton farm will consist of using surface geophysical techniques and drilling in an effort to define subsurface signatures for these three linears and their surface and subsurface characteristics.

\subsection{River Bend Farm}

The area surveyed at the River Bend Farm is dominated 


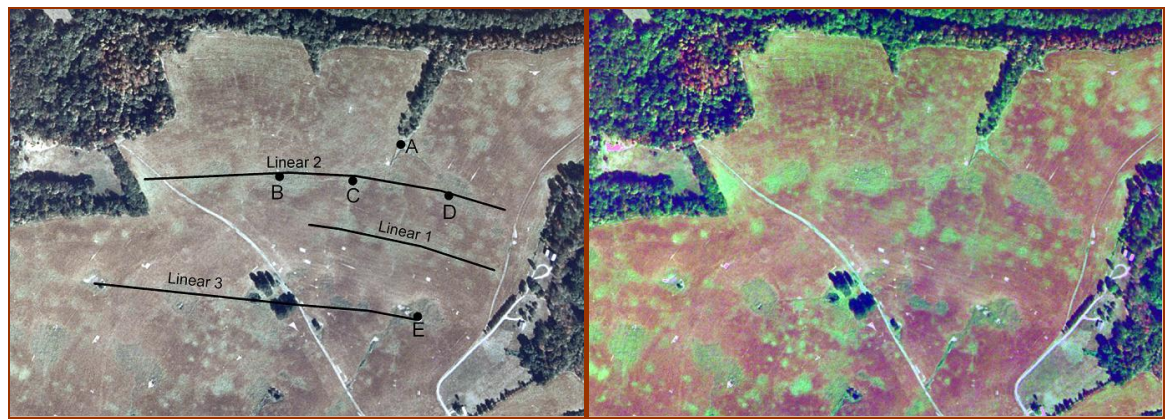

(a)

(b)

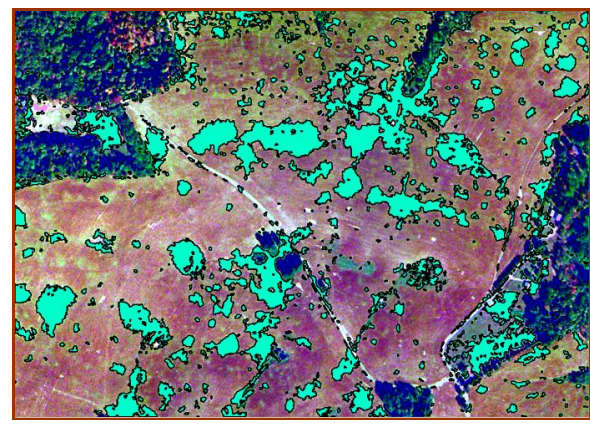

(c)

Figure 4. (a) Original NAIP imagery with linears; (b) Decorrelation-stretched image; (c) Extracted feature layer on the Newton farm.

by the Crider silt loam on 2 to 6 and 6 to 12 percent slopes, and Pembroke-Crider on 6 to 12 percent slopes mapping units, with presence of Hammack Baxter Complex on 6 to 12 percent slopes and Lindside silt loam mapping units. Similar to the Newton farm, Typic Paleudalfs dominate this area. In contrast to the Newton farm, no linears stand out on the photograph. However, there are light-green and bluish-green circular patterns that appear on the image scattered throughout the fields. Figures 9a, b and c, show the original, decorrelationstretched and extracted feature layer of the River Bend Farm. The feature layer extracted from the processed image retains the same circular patterns as the original image. A field visit to this farm in April, 2006, found the fields in wheat approximately $1 \mathrm{~m}$ in height. Although difficult to walk through and to make observations because of the density and height of the wheat, several traverses were made into the fields to look for any evidence to suggest the cause for the circular patterns. At Site 1 , a circular area of about $10 \mathrm{~m}$ in diameter, the wheat was approximately $0.6 \mathrm{~m}$ tall, noticeably stunted when compared to the wheat outside of this pattern (Figure 10).

At Site 2, there was also a noticeably oblong area of stunted wheat whereas Site 3 is just a noticeable swale approximately $15 \mathrm{~m}$ in diameter. In an interview, the farm owner stated that sinkholes open up unexpectedly in the fields, are filled in with rock and soil, and plowed around as necessary.

In early winter 2006, after the double cropped soybeans are harvested, we intend to initiate a field geophysics study across the vegetatively stressed areas delineated by the imagery and field reconnaissance in April, 2006. We anticipate that the surface geophysical techniques will define subsurface signatures for the various types of circular features seen on the imagery.

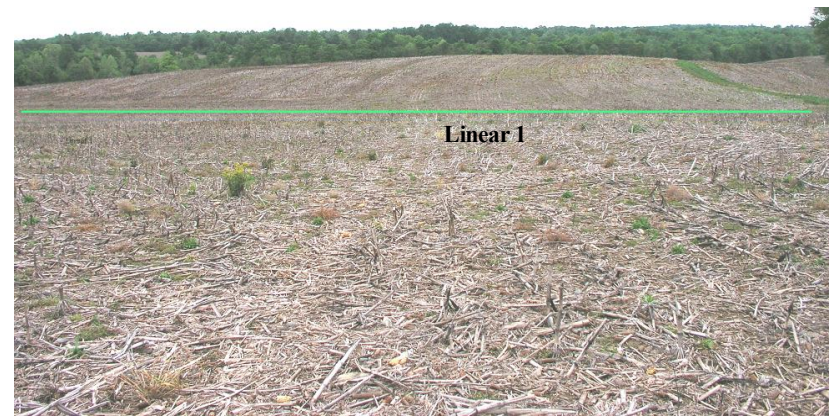

Figure 5. Photograph of corn stubble and Linear 1 on Newton farm.

\section{Conclusions}

In the eastern USA, karst sinkholes are responsible for millions of dollars of damage to buildings, infrastructures, agribusinesses, and land availabilities. Although existing sinkholes are readily identified, the location of developing sinkholes that have not yet expressed themselves at land surface 


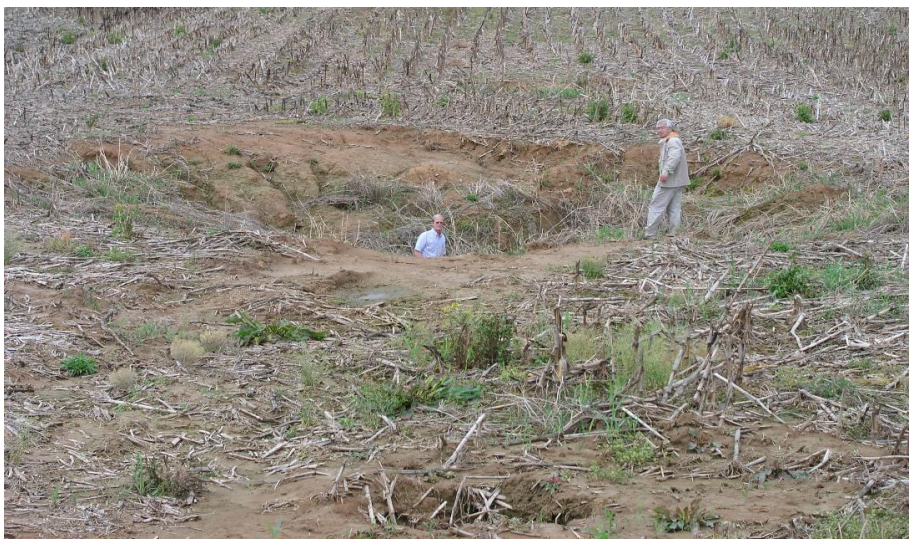

Figure 6. Photograph of sinkhole E on Linear 3 on the Newton farm.

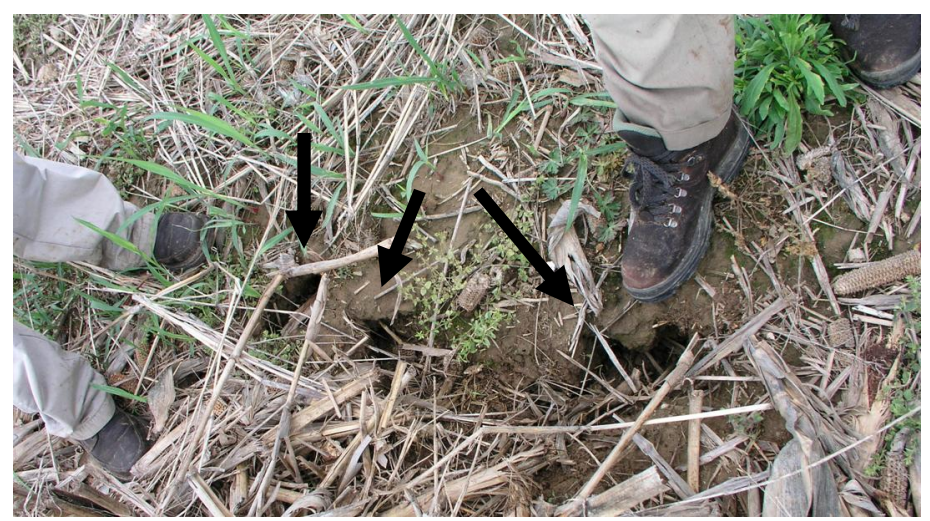

Figure 7. Photograph of epikarst swallow holes (indicated by arrows) along Linear 1 on the Newton farm.

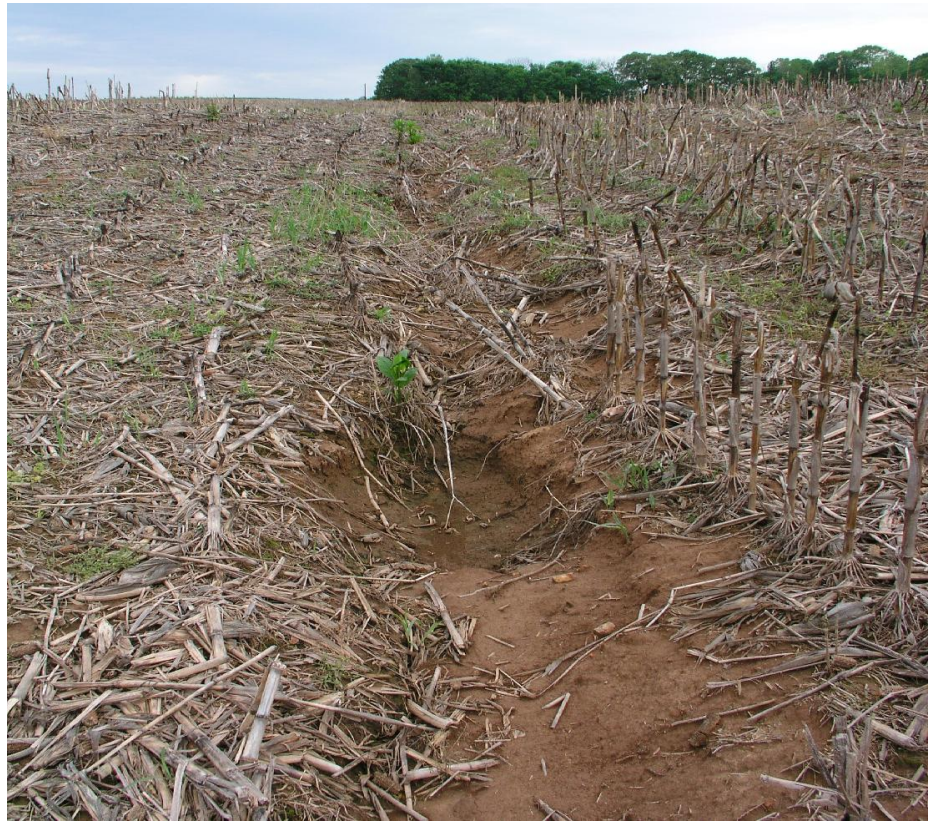

Figure 8. Photograph of the shallow erosion furrow with small knickpoint at mid-slope on Linear 2. 


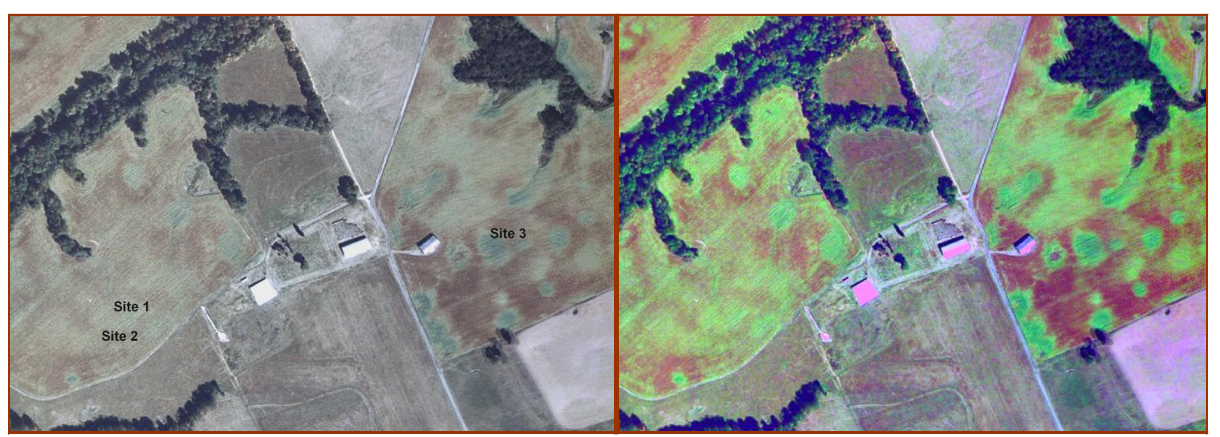

(a)

(b)

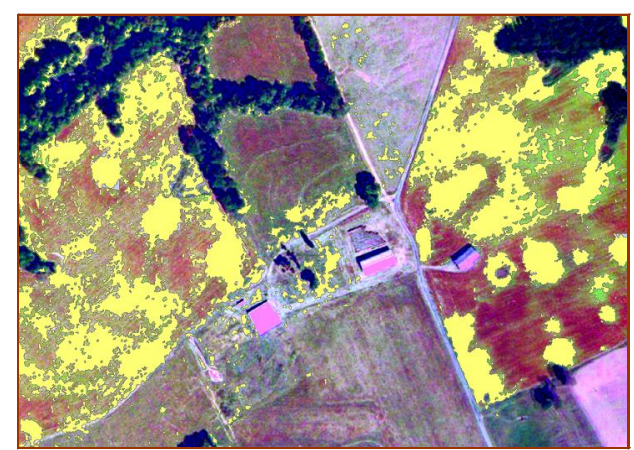

(c)

Figure 9. (a) Original NAIP imagery sites visited; (b) Decorrelation-stretched image; (c) Extracted feature layer on the River Bend Farm.

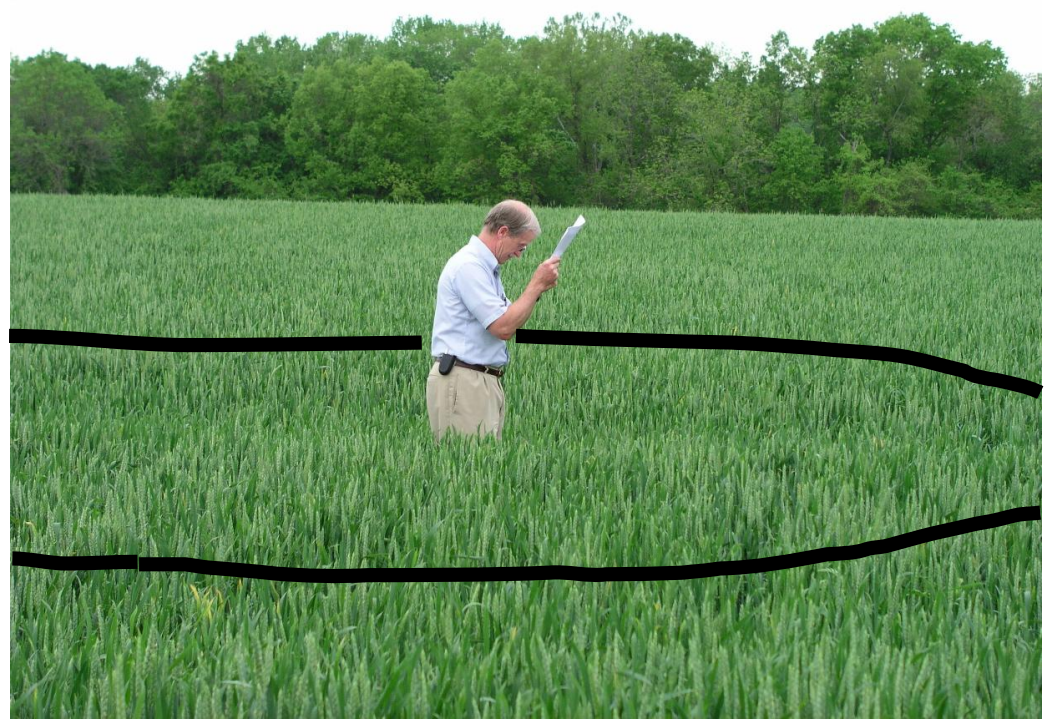

Figure 10. Photograph of Site 1 with an author standing within the area of stressed wheat as delineated by the black lines. 
through cover collapse has been a recognized, daunting problem. Drilling and geophysical techniques have successfully been employed to locate these hidden features in discrete areas. However, these techniques are not time nor cost effecttive if employed over generally-known karst terrains without having specifically targeted areas.

To target areas of potential sinkhole cover collapse, we used the national Agricultural Imagery Program imagery, 1-m ground resolution, in 3, 8-bit bands (visible, RGB). It was effective in highlighting circular features that appear to be related to sinkhole occurrence. In some instances, the features were sinkholes up to $5 \mathrm{~m}$ in depth. In other instances, the features did not represent existing sinkholes. On the Newton farm where the fields are in corn stubble, existing sinkholes appear as brownish circular features on the imagery whereas the other circular features expressed themselves in a lightgreen color. No sinkholes were observed in the latter case. For both cases, these patterns formed linear features associated with potential sinkhole development and the structural geology of the area. At the River Bend Farm, circular patterns were observed on the images by light-green and bluish-green features. No linear pattern was formed by these features. Wheat was near full growth which obscured any soil-surface features that might be related to karst. However, the farmer reported that sinkholes frequently opened up on the property. Several of the circular features observed on the imagery were found to have stunted wheat growth that may be related to soil moisture conditions that are being influence by natural processes associated with sinkhole development.

In the coming year, it is our goal to apply surficial geophysical techniques and drilling to define the subsurface characteristics of the various circular patterns and linears extracted from the imagery. It is anticipated that confirmation and correlation of image features with subsurface characteristics will help develop remote sensing techniques to delineate potential cover-collapse sinkholes before they express themselves at the surface. Development of such a tool will provide a time- and cost-effective approach to land-use planning by substantially reducing the cost of sinkhole characterization by drilling and geophysical techniques, and by reducing damage by cover collapse to anthropogenic land uses.

\section{References}

Baughman, S.H.II. (2006). Karst phase I investigations-identify sinkholes before they develop, in Geological Society of America Annual Philadelphia Meeting, Paper No. 150-7.

Crawford, N.C. and Groves, C.G. (1995). Sinkhole collapse and ground water contamination problems resulting from storm water drainage wells on karst terrain, in Proc. of Multidisciplinary Conference on Sinkholes and the Engineering and Environmental Impacts of Karst, 5, pp. 257-264.

Currens, J.C. and Graham, C.D.R. (1993). Flooding of sinking creek, garretts spring karst drainage basin, Jessamine and Woodford counties, Kentucky. Environ. Geol., 22(4), 337-344.
Currens, J.C. (1999). Mass flux of agricultural nonpoint-source pollutants in a conduit-flow dominated karst aquifer, Logan County, Kentucky Geological Survey, Series 12, Report of Investigations 1, pp. 151.

Currens, J.C., Paylor, R.A. and Ray, J.A. (2003). Mapped karst ground-water basins in the Harrodsburg $30 \times 60$ minute quadrangle, Kentucky Geological Survey, Series 12, Map and Chart Series 58, 1:100,000-scale.

Currens, J.C., Paylor, R.L. and Crawford, M.M. (2005). Karst potential and development indices: Tools for mapping karst using GIS, in Southeast Section Annual Meeting, Biloxi, Mississippi, 37(2), pp. 48.

Dinger, J. and Rebmann, J. (1986). Ordinance for the control of urban development in Sinkhole areas in the Blue Grass Region, Lexington, Kentucky, in Environmental Problems in Karst Terranes and their Solutions, National Water Well Association, Bowling Green, Kentucky, pp. 163-179.

Fox, K.R. (1965). Geology of the Cadiz Quadrangle, Trigg County, Kentucky, US Geological Survey 7.5 Minute Geologic Quadrangle Map, GQ-412.

Gillespie, A.R., Kahle, A.B. and Walker, R.E. (1986). Color enhancement of highly correlated images: I. Decorrelation and HSI contrast stretches. Remote Sens. Environ., 20, 209-235.

Humphrey, M.E. (1981). Soil survey of Lyon and Trigg Counties, US Government Printing Office, 327-804/81.

Lillesand, T.M., Kiefer, R.W. and Chipman, J.W. (2004). Remote Sensing and Image Interpretation, 5th Edition, John Wiley \& Sons, New York, pp. 763.

O'Brien, M.A. (2003). Feature extraction with the VLS feature analyst system, in Proc. of ASPRS International Conference, Anchorage, AK, USA.

Rouse, K.J., Palmer, J.R. and Young, G. (2004). Multispectral image analysis as a guide to identifying potential soil-bedrock karst collapse hazards in urban settings, in Geological Society of America, 36(3), 6.

Sowers, G.F. (1996). Building on Sinkholes: Design and Construction of Foundations in Karst Terrain, American Society of Civil Engineers Press, New York, pp. 202

Stombaugh, T.S., Simpson, A., Jacobs, J.D. and Mueller. T.G. (2003). A low cost platform for obtaining remote sensed imagery, in Proc. of the Fourth European Conference on Precision Agriculture, Berlin, Germany, pp. 665-670.

Taraba, J.L., Dinger, J.S., Sendlein, L.V.A. and Felton, G.K. (1997). Land use impacts on water quality in small karst agricultural watersheds, in Proc. Karst-Water Environment Symposium, Virginia Polytechnic Institute and State University, Roanoke, Virginia, pp. 99-109.

Veni, G. and Crawford, N.C. (1988). Sinkhole collapse inventory of the central Kentucky karst, methodology and preliminary results. Central Kentucky Cave Survey Bull., 2, 59-72.

White, W.B. and White, E.L. (1992). Sinkholes and sinkhole collapses, in Natural and Technological Disasters: Causes, Effects, and Preventive Measures, The Pennsylvania Academy of Science, pp. 280-293.

Woods, R.D. (Ed.) (1994). Geophysical Characterization of Sites, ISSMFE Technical Committee 10, Oxford and IBHI Publishing, New Delhi, India. 